Relations industrielles

Industrial Relations

\title{
Liberté et sécurité syndicales
}

\section{Jacques Archambault}

Volume 5, numéro 6, mars 1950

URI : https://id.erudit.org/iderudit/1023348ar

DOI : https://doi.org/10.7202/1023348ar

Aller au sommaire du numéro

\section{Éditeur(s)}

Département des relations industrielles de l'Université Laval

ISSN

0034-379X (imprimé)

1703-8138 (numérique)

Découvrir la revue

Citer cet article

Archambault, J. (1950). Liberté et sécurité syndicales. Relations industrielles / Industrial Relations, 5(6), 55-55. https://doi.org/10.7202/1023348ar

Tous droits réservés ( Département des relations industrielles de l’Université Laval, 1950
Ce document est protégé par la loi sur le droit d'auteur. L’utilisation des services d'Érudit (y compris la reproduction) est assujettie à sa politique d'utilisation que vous pouvez consulter en ligne.

https://apropos.erudit.org/fr/usagers/politique-dutilisation/ 


\title{
LIBERTÉ ET SÉCURITÉ SYNDICALES
}

\author{
Jacques Archambault
}

La sécurité syndicale repose toute entière sur la liberté syndicale. Plusieurs définissent ainsi la liberté syndicale: "Cette liberté pour un patron ou un ouvrier de faire partie ou de ne pas faire partie d'un syndicat de son choix ». C'est là une belle définition pseudophilosophique, mais, sociologiquement parlant, cette définition est fausse, parce qu elle ne tient pas compte des données expérimentales que la réalité fournit sur ce point.

La liberté «in se»n'est pas un principe absolu, car, liberté présuppose une adhésion libre. Les tenants conscients ou inconscients du libéralisme économique affirment: «Si je suis libre d'adhérer, je suis également libre de ne pas adhérer ». Voilà apparemment de beaux raisonnements théoriques et dialectiques, mais la réalité sociale s'accommode mal de ce genre de logique et de dialectique.

En autant que le fait syndical est concerné, on peut affirmer que le principe de liberté joue uniquement dans un sens positif, c'est-à-dire qu'il n'est là que pour protéger l'exercice d'un droit et rappeler l'existence d'un devoir. En effet, le concept de liberté syndicale doit tenir compte du principe général qui affirme que «dans l'état actuel des choses, les associations syndicales sont moralement nécessaires $\gg{ }^{1} \quad$ S’il est expérimentalement prouvé que le syndicalisme, actuellement, est moralement nécessaire, il est donc de nécessité « de moyen » de faire partie d'un syndicat patronal et ouvrier pour réaliser les objectifs sociaux actuels commandés par la philosophie sociale chrétienne. Il ne saurait donc être question de définir la liberté syndicale comme «cette faculté de ne pas appartenir au syndicat de son choix», parce qu'en plus d'être un droit fondamental, l'appartenance à un syndicat devient une obligation morale, un devoir social impérieux.

Il peut arriver, parfois, que les circonstances deviennent principes daction. Les circonstances peuvent ainsi commander la réalisation pratique d'un ordre de choses. La liberté restera toujours principe relatif, mais l'application, l'usage du principe de liberté syndicale peut comporter, à un moment donné, un caractère d'obligation.

Pour se faire reconnaître et se faire accepter de tous à l'heure actuelle, le syndicalisme, à cause de sa nature même, doit prendre non seulement des moyens juridiques mais aussi des moyens psy-

(1) Lettre de la Sacrée Congrégation du Concile à Mgr Liénart, 5 juin 1929. chologiques. Les clauses de sécurité syndicale réalisent ces deux catégories de moyens: elles constituent un moyen, pour tel syndicat, de se faire concrètement et juridiquement reconnaître par tel employeur; d'autre part, elle est également pour lui un moyen psychologique de se faire connaître, de saffirmer vis-à-vis l'opinion publique autant que vis-à-vis l'employeur et les ouvriers eux-mêmes. Le mouvement syndical est un mouvement de masse, il doit donc employer des moyens «massifs» pour promouvoir sa cause, sans pour cela faire du tort à qui que ce soit.

Ce n'est pas là une atteinte à la liberté individuelle de l'ouvrier, comme plusieurs le prétendent. Tout groupe social a besoin de cadres pour vivre et grandir; l'individu du XXième siècle doit s'épanouir à l'intérieur de cadres sociaux déterminés. L'atelier fermé, l'atelier syndical, la formule Rand, ce n'est pas à proprement parler le «crois ou meurs» mais c'est le «crois et vis». Tu vivras par le syndicalisme et tu mourras par l'isolement.

La personnalité de l'individu est sauvegardée grâce à la souplesse de la doctrine syndicale ellemême et surtout par sa concordance avec l'utilité commune; le syndicat patronal ou ouvrier c'est, pour ainsi dire, un médium de distribution d'avantages et de contribution au bien social pour le patron et l'ouvrier modernes: c'est, de toute évidence, une institution de Bien commun.

Liberté syndicale et sécurité syndicale sont donc intimement liées l'un à l'autre. «In se» toutes deux sont des notions relatives, mais, considérées et examinées en regard des circonstances actuelles, la première devient une norme d'action dans un sens positif et la deuxième apparaît comme une pièce maîtresse essentielle de la structure sociale; elles deviennent des principes fondamentaux et absolus et toutes deux sont essentielles à la réalisation du bien commun de la société toute entière. C'est pourquoi il importe d'avoir de ces idées une conception juste ct réaliste. Les prises de position dans le domaine des théories sociales doivent être basées sur l'étude des principes et des fait sociaux, ne l'oublions pas. C'est ce qui a amené la Conférence internationale du travail de San Francisco à conclure que «le droit de s'organiser ou de ne pas s'organiser ne saurait être mis sur un même pied ». ${ }^{2}$

(2) Vingt-septième session du Congrès de la CTCC, rapport du Président général, procès-verbal, p. 39 . 